ARTICLE

https://doi.org/10.1038/s41467-019-12900-4

\title{
Printable magnesium ion quasi-solid-state asymmetric supercapacitors for flexible solar-charging integrated units
}

\author{
Zhengnan Tian ${ }^{1,6}$, Xiaoling Tong ${ }^{1,6}$, Guan Sheng ${ }^{2}$, Yuanlong Shao ${ }^{2 \star}$, Lianghao Yu1 , Vincent Tung ${ }^{2}$, Jingyu Sun ${ }^{1,3 \star}$,
} Richard B. Kaner ${ }^{4 \star} \&$ Zhongfan Liu (i) 1,3,5

Wearable and portable self-powered units have stimulated considerable attention in both the scientific and technological realms. However, their innovative development is still limited by inefficient bulky connections between functional modules, incompatible energy storage systems with poor cycling stability, and real safety concerns. Herein, we demonstrate a flexible solar-charging integrated unit based on the design of printed magnesium ion aqueous asymmetric supercapacitors. This power unit exhibits excellent mechanical robustness, high photo-charging cycling stability ( $98.7 \%$ capacitance retention after 100 cycles), excellent overall energy conversion and storage efficiency $\left(\eta_{\text {overall }}=17.57 \%\right)$, and outstanding input current tolerance. In addition, the $\mathrm{Mg}$ ion quasi-solid-state asymmetric supercapacitors show

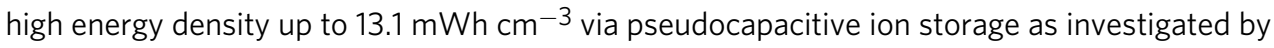
an operando $X$-ray diffraction technique. The findings pave a practical route toward the design of future self-powered systems affording favorable safety, long life, and high energy.

\footnotetext{
${ }^{1}$ College of Energy, Soochow Institute for Energy and Materials InnovationS (SIEMIS), Jiangsu Provincial Key Laboratory for Advanced Carbon Materials and Wearable Energy Technologies, Soochow University, 215006 Suzhou, P. R. China. ${ }^{2}$ College Physical Sciences and Engineering Division, King Abdullah University of Science and Technology, Thuwal 23955-6900, Saudi Arabia. ${ }^{3}$ Beijing Graphene Institute (BGI), 100095 Beijing, P. R. China. ${ }^{4}$ Department of Chemistry and Biochemistry, Department of Materials Science and Engineering, and California NanoSystems Institute, University of California, Los Angeles (UCLA), Los Angeles, CA, USA. ${ }^{5}$ Center for Nanochemistry (CNC), College of Chemistry and Molecular Engineering, Peking University, 100871 Beijing, P. R. China. ${ }^{6} T h e s e$ authors contributed equally: Zhengnan Tian, Xiaoling Tong. *email: yuanlong.shao@gmail.com; sunjy86@suda.edu.cn; kaner@chem.ucla.edu
} 
$\mathrm{T}$ he growing demand for miniaturization and multifunctionalization of portable electronics has spurred the development of integrated energy systems that can hybridize energy harvesting and storage in a flexible and even wearable fashion ${ }^{1}$. In terms of energy-harvesting modules, photovoltaic (PV) devices, especially silicon solar cells, have become ubiquitous for harnessing clean and accessible solar energy. However, due to the intermittent and unpredictable nature of sunlight, the fluctuating output energy of PV panels is highly unlikely to support the direct powering of wearable electronics; thus, energy needs to be stored in a reliable module for further use on demand. Among a plethora of emerging energy storage technologies, supercapacitors offer high power density and excellent tolerance to the variation of input current, thereby being perfect for accommodating PV modules for building efficient self-powered platforms ${ }^{2}$. Despite these meritorious properties, supercapacitors suffer from relatively low energy density when compared with metal-ion battery systems, which significantly impedes their applications in the realm of wearable technology. In this regard, developing asymmetric supercapacitors (ASCs) remains a feasible solution: their extended operating voltage favors enhanced energy density without sacrificing high power capability and good current tolerance; hence, benefiting the overall performance of PVsupercapacitor integrated systems ${ }^{3}$. Recently, Zhang et al. ${ }^{4}$ demonstrated a flexible photo-capacitor based on a $\mathrm{Co}_{9} \mathrm{~S}_{8}-$ $\mathrm{MnO}_{2} / / \mathrm{TiO}_{2}$ asymmetric electrode design. In our previous work, a wearable photo-rechargeable lithium-ion hybrid capacitor (LIC) also demonstrated a high overall efficiency up to $8.41 \% 5$.

Safety is the primary concern for wearable energy systems, which therefore demand aqueous electrolytes along with nonflammable electrodes. Although it is difficult for an aqueous electrolyte system to achieve a high working voltage compared to organic electrolytes $(2.5-4.0 \mathrm{~V})$, the two order of magnitude greater ionic conductivity endows it with fast ion transport and hence, high-rate performance. Furthermore, it is interesting to note that neutral aqueous electrolyte-based ASCs can achieve a wide working voltage from $\sim 1.6$ to $2.0 \mathrm{~V}$, which exceeds the theoretical limit of the water splitting potential, $1.23 \mathrm{~V}$. Such a large operating voltage is achieved by high hydrogen and oxygen evolution overpotentials in a neutral aqueous system. Of particular note, these neutral electrolytes readily overcome the hazardous concerns of flammability and corrosion that occur with organic and acidic/alkaline electrolytes; thus, overcoming the substantial safety issues encountered with wearable devices. As such, exploiting neutral electrolytes with multivalent metal-ions $\left(\mathrm{Mg}^{2+}, \mathrm{Al}^{3+}, \mathrm{Zn}^{2+}, \mathrm{Ca}^{2+}\right.$, etc.) for aqueous ASCs represents a promising strategy to synchronously address the safety challenges while boosting energy density 6,7 . However, until now, the development of a wearable solar-charging power unit employing multivalent metal-ion ASCs based on directly printing designs is still in its nascent stage, and hence in need of systematic exploration.

Herein, we devise aqueous Mg ion ASCs targeting the construction of wearable solar-charging integrated power units. Such flexible, quasi-solid-state ASCs $\left(\mathrm{MnO}_{2} / / \mathrm{VN}\right)$ are assembled with nanoflower-like $\mathrm{MnO}_{2}$ as the positive electrode, nanowire-shaped $\mathrm{VN}$ as the negative electrode, and $\mathrm{MgSO}_{4}-\mathrm{PAM}$ gel as the electrolyte, synergistically achieving a wide potential window (up to $2.2 \mathrm{~V}$ ), favorable volumetric energy density (up to $13.1 \mathrm{mWh} \mathrm{cm}^{-3}$ ), high power density (up to $440 \mathrm{~mW} \mathrm{~cm}^{-3}$ ), and outstanding cycling stability (capacitance retention up to $95 \%$ after 5000 cycles). The $\mathrm{Mg}$ ion electrochemical system developed in this work has the following attributes: (i) a superior charge storage efficiency due to the dual-electron transfer possible with $\mathrm{Mg}^{2+}$-ion intercalation in comparison with typical alkali metal-ion $\left(\mathrm{Li}^{+}, \mathrm{Na}^{+}, \mathrm{K}^{+}\right)$systems; (ii) a facile redox process enabled by the highly efficient surface ion migration and near-surface ion intercalation of nano-sized $\mathrm{MnO}_{2}$ and VN; and (iii) a wider voltage window owing to the negative hydrogen evolution reaction overpotential on $\mathrm{VN}$ surfaces. The $\mathrm{Mg}$ ion transport mechanism at the $\mathrm{VN}$ anode is further probed using operando X-ray diffraction (XRD) and ex situ X-ray photoelectron spectroscopy (XPS) techniques. Moreover, direct printing of such device arrays on the rear of flexible solar cells enables the fabrication of solar-charging power units with simplified configurations and mechanical robustness. Importantly, the printable and flexible integrated system thusderived shows remarkable mechanical robustness, excellent photo-charging cycling stability $(98.7 \%$ capacitance retention after 100 cycles), and efficient powering of electronic devices (e.g. a smart watch and a light-emitting diode), demonstrating great potential as self-powered wearable energy sources for safe use in practical scenarios.

\section{Results}

Illustrating the configuration of solar-charging units. Figure 1a (i) illustrates the configuration of a flexible solar-charging selfpowered unit, encompassing an energy-harvesting module (i.e. a flexible solar cell), an energy storage module (i.e. a printed quasisolid-state ASC array on a polyimide substrate), and a plastic film capping layer. Note in Fig. 1a (ii) that the quasi-solid-state ASC is assembled by using vanadium nitride $(\mathrm{VN})$ as the negative electrode, manganese oxide $\left(\mathrm{MnO}_{2}\right)$ as the positive electrode, and $\mathrm{MgSO}_{4}$-polyacrylamide (PAM) gel as the electrolyte. Such an aqueous supercapacitor device is operated based on the pseudocapacitive intercalation/de-intercalation of $\mathrm{Mg}^{2+}$ ions between $\mathrm{VN}$ and $\mathrm{MnO}_{2}$ electrodes. For the integrated unit, upon exposure to sunlight, the solar cell component enables the conversion of photo-irradiation into electricity and charges the supercapacitor simultaneously (photo-charging). The photo-charged supercapacitor can provide stored power for electronic devices anytime on demand (discharging). In addition, the entire integrated system complies with a thin-film planar design, which endows it with good flexibility. As a proof-of-concept demonstration, a solar-charging self-powered unit can be directly worn and function as a reliable power source for powering a portable electronic watch, as shown in Fig. 1a (iii).

Characterizing as-prepared VN nanowires. The synthetic route to $\mathrm{VN}$ nanowires was adopted from a reported recipe (Supplementary Fig. 1a) ${ }^{8}$. Scanning electron microscopy (SEM; Fig. 1b) images show the typically porous nanowire structure of $\mathrm{VN}$, with uniform $120-150 \mathrm{~nm}$ in width and $\sim 2 \mu \mathrm{m}$ in length. Transmission electron microscopy (TEM; Fig. 1c) presents the detailed morphology of the porous VN nanowires, showing many interconnected open pores. Elemental mapping of the as-prepared VN reveals a homogeneous distribution of nitrogen and vanadium (Supplementary Fig. 1b). The appearance of an oxygen signal suggests the existence of surface-bound oxygen upon exposure to air. Further XPS analysis indicates the dominance of the $\mathrm{V}^{3+}$. binding state as well as the V-N signal (Supplementary Fig. 1c, d), implying the successful fabrication of VN. Note that there are no XPS peaks indicative of $\mathrm{V}^{4+}$ and $\mathrm{V}^{5+}$ states, which can be attributed to the excessive reduction from the long-term and high-temperature $\mathrm{NH}_{3}$ annealing process $\left(600{ }^{\circ} \mathrm{C}\right.$ for $\left.3 \mathrm{~h}\right)$. Aberration-corrected scanning transmission electron microscopy (STEM) observations display the lattice fringes of VN (Fig. 1c inset; Supplementary Fig. $1 \mathrm{e}-\mathrm{g}$ ), with a lattice spacing of $0.21 \mathrm{~nm}$ matching well with the VN (200) plane. Figure 1d depicts the Xray diffraction (XRD) pattern of synthesized VN samples. Characteristic peaks are found at $37.9^{\circ}(111), 44.0^{\circ}$ (200), and $64.1^{\circ}(220)$, verifying the well-defined crystal structure of $\mathrm{VN}$ 
a
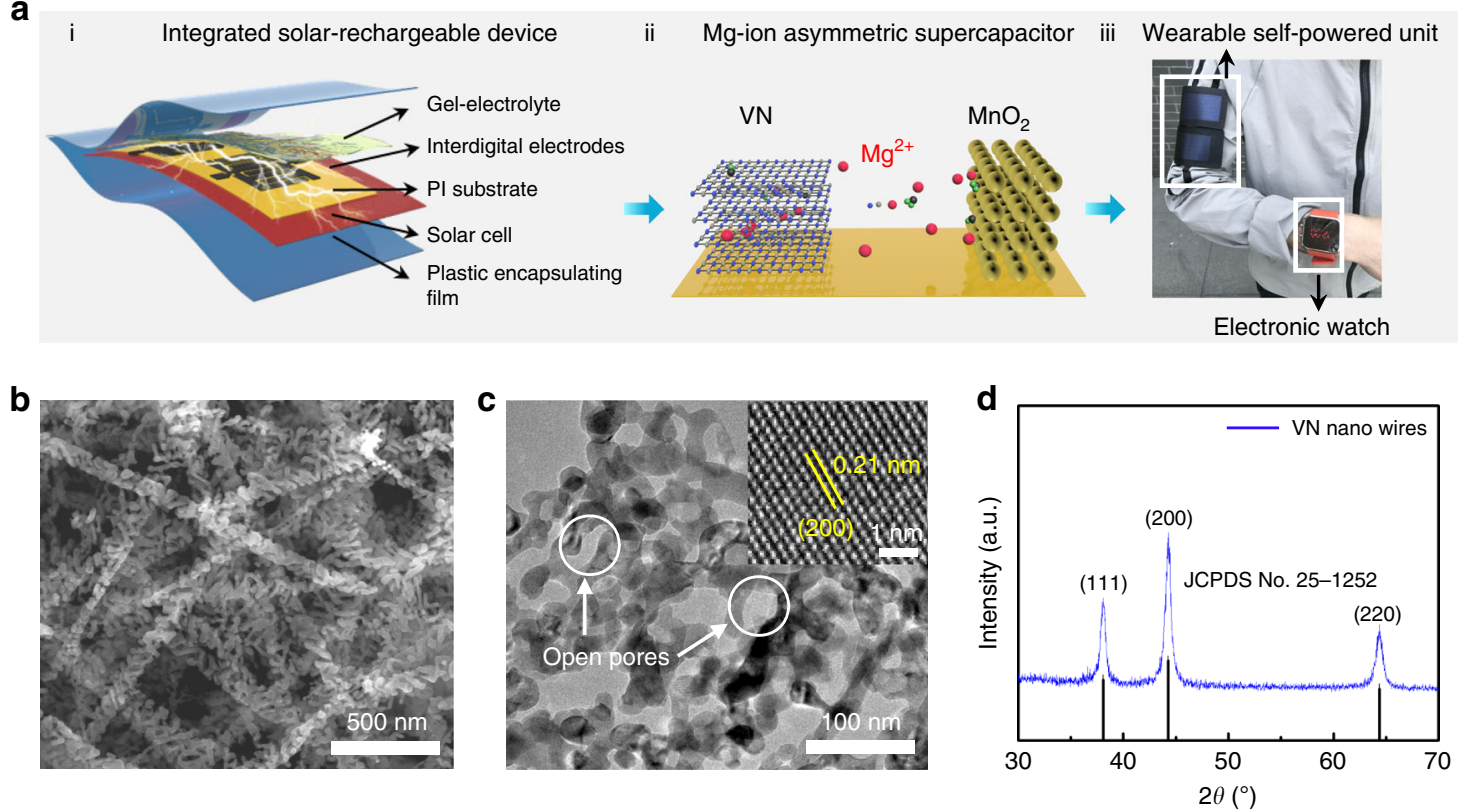

Fig. 1 Schematic illustration of the solar-charging integrated unit and characterization of VN nanowires. a Configuration of the solar-charging self-powered unit and proof-of-concept demonstration of wearable applications. b SEM image of as-prepared porous VN nanowires. c TEM image of VN nanowires. Inset: High-resolution STEM image. $\mathbf{d}$ XRD pattern of VN

(JCPDS No. 25-1252). It is anticipated that such nanowire-shaped $\mathrm{VN}$ is key to achieving favorable electrochemical performances when used as electrodes due to: (1) the large aspect ratio, intrinsic porous structure, and nanometer sized dimensions $(<20 \mathrm{~nm})$ of the $\mathrm{VN}$ nanowires which endow them with high-rate capabilities and near-surface $\mathrm{Mg}^{2+}$ intercalation pseudo-capacitive behavior, a crucial factor for their superior rate capability and cycling stability. (2) the nanowire-shaped microstructure could become interwoven with each other thereby avoiding aggregation upon cycling, which has often been seen when using nanoparticle or nanosheet morphologies.

Investigating electrochemical properties of $\mathrm{VN}$ nanowires. The electrochemical performance of $\mathrm{VN}$ was systematically examined via a three-electrode cell system. Cyclic voltammetry $(\mathrm{CV})$ measurements at a scan rate of $10 \mathrm{mV} \mathrm{s}^{-1}$ were carried out in various neutral aqueous electrolytes affording identical cation concentrations (Fig. 2a), including $0.5 \mathrm{M} \mathrm{Li}_{2} \mathrm{SO}_{4}, 0.5 \mathrm{M} \mathrm{Na}_{2} \mathrm{SO}_{4}$, $0.5 \mathrm{M} \mathrm{K}_{2} \mathrm{SO}_{4}$, and $1.0 \mathrm{M} \mathrm{MgSO}_{4}$. It is interesting to note that the $\mathrm{VN}$ electrode exhibits the largest $\mathrm{CV}$ area in the $\mathrm{Mg}$ ion electrolyte. Figure $2 \mathrm{~b}$ summarizes the gravimetric-specific capacitances calculated based on the $\mathrm{CV}$ profiles. The VN electrode manifests a specific capacitance of $230 \mathrm{~F} \mathrm{~g}^{-1}$ in the $\mathrm{MgSO}_{4}$ electrolyte, far superior to those achieved in $\mathrm{Li}_{2} \mathrm{SO}_{4}\left(120 \mathrm{~F} \mathrm{~g}^{-1}\right)$, $\mathrm{Na}_{2} \mathrm{SO}_{4}\left(100 \mathrm{Fg}^{-1}\right)$, and $\mathrm{K}_{2} \mathrm{SO}_{4}\left(70 \mathrm{Fg}^{-1}\right)$. Such markedly enhanced capacitance in the $\mathrm{Mg}^{2+}$ electrolyte mainly stems from the following factors: (i) the bivalent metal-ion $\left(\mathrm{Mg}^{2+}\right)$ possesses a higher theoretical capacitance due to dual-electron transfer during redox reactions. The possible Faradaic reactions of VN in an aqueous $\mathrm{Mg}^{2+}$ electrolyte can be described as follows?:

$$
\mathrm{VN}_{x} \mathrm{O}_{y}+z \mathrm{Mg}^{2+}+z 2 \mathrm{e}^{-} \leftrightarrow \mathrm{VN}_{x} \mathrm{O}_{y} \mathrm{Mg}_{z}
$$

In this respect, the capacitance stored in the $\mathrm{Mg}^{2+}$ system should be twice that of other monovalent cation systems, which is in good agreement with the capacitance derived from the $\mathrm{CV}$ measurements. (ii) The relatively smaller ionic radius of $\mathrm{Mg}^{2+}$ ions $\left(\mathrm{Mg}^{2+}: 0.72 \AA, \mathrm{Li}^{+}: 0.76 \AA, \mathrm{Na}^{+}: 1.02 \AA, \mathrm{K}^{+}: 1.51 \AA\right)^{10}$ leads to pseudo-capacitive-dominated charge storage behavior of the VN electrode.

Electrochemical impedance spectroscopy (EIS) studies offer further insights into the ionic and electronic transport properties of the VN electrode in different cation electrolytes (Supplementary Fig. 2a, b). At the low-frequency region, the steep shape of the straight lines reveals a typical capacitive behavior in various electrolytes. At the high-frequency region, the internal resistance $\left(R_{\mathrm{s}}\right)$ shows obvious differences $\left(\mathrm{K}^{+}: 4 \Omega, \mathrm{Na}^{+}: 5.5 \Omega, \mathrm{Li}^{+}: 7 \Omega\right.$, $\left.\mathrm{Mg}^{2+}: 8.5 \Omega\right) . R_{\mathrm{s}}$ normally consists of the conductive resistance of the electrolyte, as well as the intrinsic contact resistance between electrode material and current collector. Since all the Nyquist plots were acquired based on the same electrode material and electrochemical cell configuration, the difference of $R_{\mathrm{s}}$ should be mainly attributed to the diverse conductive resistances of different cation electrolytes. Because of its bivalent nature and small ionic radius, $\mathrm{Mg}^{2+}$ ions exhibit relatively strong ionic bonds. Therefore, the diffusion of $\mathrm{Mg}^{2+}$ ions is more sluggish than that of monovalent cations. The higher resistance polarization of $\mathrm{Mg}^{2+}$ should result in a larger voltage hysteresis, which is helpful in extending the stable working voltage of $\mathrm{VN}$ in the $\mathrm{Mg}^{2+}$ electrolyte system. A Randles equivalent circuit with relative parameters is provided (Supplementary Fig. 2c; Supplementary Table 1), accompanied by the detailed discussions shown in Supplementary Note 1. Figure 2c displays the linear sweep voltammetry (LSV) polarization curves of a VN electrode in different cation electrolytes. It is evident that the $\mathrm{Mg}^{2+}$ system manifests the highest overpotential for hydrogen evolution. Along this line, the stable working voltage of the $\mathrm{VN}$ electrode in an $\mathrm{Mg}^{2+}$ electrolyte can be extended, corroborating the EIS analysis. Figure $2 \mathrm{~d}$ summarizes the specific capacitances of $\mathrm{VN}$ in the $\mathrm{Mg}^{2+}$ electrolyte that correspond to the CV profiles at different scan rates (Fig. 2d, inset). The $\mathrm{CV}$ shapes are well maintained upon increasing the scan rate from 1 to $200 \mathrm{mV} \mathrm{s}^{-1}$, indicating the favorable rate performance of the $\mathrm{VN}$ electrode in the $\mathrm{Mg}^{2+}$ system. Note that the redox peak between -0.6 and $-0.7 \mathrm{~V}$ only displays a slight shift when increasing the scan rates, indicating 
a
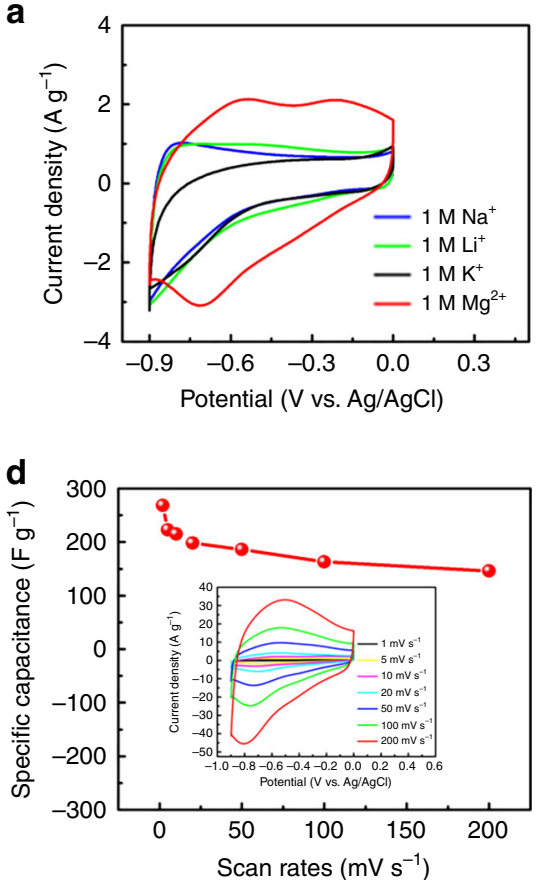
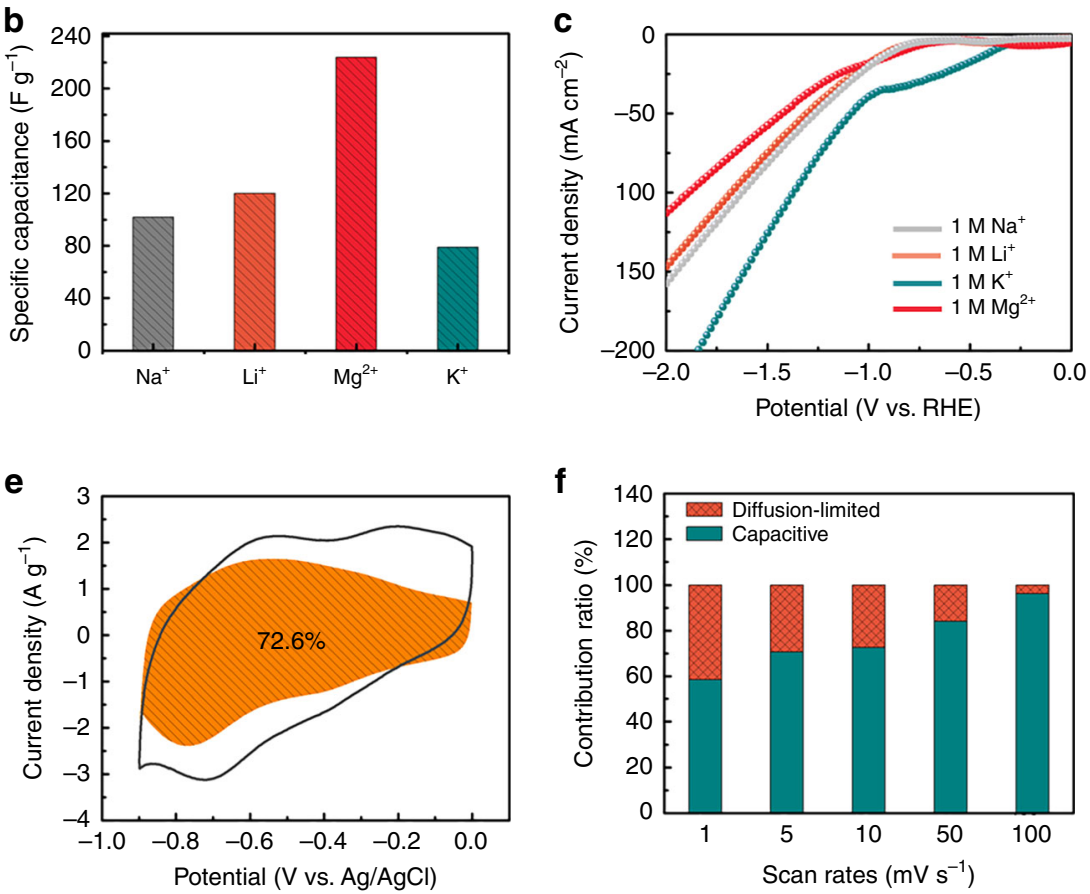

Fig. 2 Electrochemical characterization of $\mathrm{VN}$ in a three-electrode configuration. a CV curves measured in different cation-based electrolytes at the same scan rate of $10 \mathrm{mV} \mathrm{s}^{-1}$. b Corresponding gravimetric specific capacitances calculated from a in different electrolytes. c Polarization curves of a VN electrode in different cation-based neutral electrolytes. d Specific capacitances of $\mathrm{VN}$ in $1.0 \mathrm{M} \mathrm{MgSO}_{4}$ electrolyte at different scan rates. Inset: Corresponding CV curves at different scan rates. e Capacitive and diffusion-controlled contributions to the total charge storage of $\mathrm{VN}$ in $1.0 \mathrm{M} \mathrm{MgSO}_{4}$ at $10 \mathrm{mV} \mathrm{s}^{-1}$.

f Normalized contribution ratio of capacitive (cyan) and diffusion-controlled (orange) capacities at different scan rates

facile reaction kinetics during charge storage. As such, the charge stored by the Faradaic diffusion-controlled or non-Faradaic capacitive-tailored contributions can be analyzed by a $b$-value, which can be derived based on the equation $i=a v^{b 11}$. In this sense, the $b$-value is respectively calculated at 0.91 and 0.90 for the anodic and cathodic peak (Supplementary Fig. 2d), implying that the contribution from capacitive behavior dominates. To further identify the contribution ratio, the current response can be expressed by combining the two separate mechanisms (surface capacitive behavior and diffusion-controlled $\mathrm{Mg}^{2+}$ insertion processes): $i(V)=k_{1} v+k_{2} v^{1 / 2}$. Herein, $k_{1} v$ and $k_{2} v^{1 / 2}$ represent the capacitive- and diffusion-controlled current contributions, respectively. Figure $2 \mathrm{e}$ plots a capacitive current contribution at a CV scan of $10 \mathrm{mV} \mathrm{s}^{-1}$, exhibiting a large percentage of capacitance (72.6\%). In addition, Fig. $2 \mathrm{f}$ presents the bar chart of calculated capacitive contributions at various scan rates. Obviously, the ratio of capacitive contribution increases (from $60 \%$ to $98 \%$ ) as the scan rate is raised from 1 to $100 \mathrm{mV} \mathrm{s}^{-1}$, further verifying the capacitive-dominated reaction mechanism of the $\mathrm{VN}$ electrode.

Probing the electrochemical reaction mechanism of VN. To explore the reaction mechanism of the $\mathrm{Mg}^{2+}$ ions on the $\mathrm{VN}$ electrode, operando XRD analysis was performed by using $\mathrm{VN}$ as the target electrode and $\mathrm{MnO}_{2}$ as the counter electrode. All the XRD patterns were collected from the second cycle upon charge/ discharge to avoid the irreversible reactions that occurred during the first cycle. Note that there are no new phases detected during the entire charge/discharge process. Figure $3 \mathrm{a}$ documents the obvious peak shift for the VN (200) plane $\left(2 \theta: 44-45^{\circ}\right)$. Upon charging $(0-2.2 \mathrm{~V})$, the diffraction peak gradually shifts toward high angles $\left(2 \theta: 44.5-44.7^{\circ}\right)$, indicating the contraction of the interplanar distance along the (200) direction. In response, the diffraction peak returns to the low angle position upon discharging, indicating an expansion of the lattice spacing. The interplanar distance is calculated according the Bragg equation $(\lambda=$ $0.15406 \mathrm{~nm})$, to reversibly increase by $0.2 \AA(2.1 \rightarrow 1.9 \rightarrow 2.1 \AA)$ during the charge/discharge process (as depicted in Fig. $3 b$ ). Such a periodic variation in the lattice spacing confirms the reversible pseudo-capacitive $\mathrm{Mg}$ ion intercalation/de-intercalation of the VN (200) plane without causing a phase transition ${ }^{11}$. At the same time, the contraction of the interplanar distance during the $\mathrm{Mg}$ ion pseudo-capacitive intercalation can be explained by an increase of the electrostatic attraction between the guest $\mathrm{Mg}$ ions and the host $\mathrm{VN}$ lattice $\mathrm{e}^{12-14}$.

The pseudo-capacitive $\mathrm{Mg}$ ion intercalation mechanism of the $\mathrm{VN}$ electrode was verified by ex situ Mg $1 s$ XPS measurements. As shown in Fig. $3 c$, the seven different sampling points are taken from a CV scan with a scan rate of $5 \mathrm{mV} \mathrm{s}^{-1}$. The $\mathrm{Mg} 1 \mathrm{~s}$ peak is centered at $1303.3 \mathrm{eV}$, which can be assigned to $\mathrm{Mg}^{2+}$. As for the charging process (going from point 1 to 5), a gradual increase of the peak intensity can be clearly observed, reflecting the intercalation of $\mathrm{Mg}^{2+}$ ions. During the discharging process (from -0.9 to $0 \mathrm{~V}$ ), a decline in signal intensity signifies $\mathrm{Mg}^{2+}$ deintercalation. Furthermore, ex situ V $2 p$ XPS spectra reveal the valence state change of vanadium upon charge/discharge (Supplementary Fig. 3). The peaks at 515.4 and $513.2 \mathrm{eV}$ represent the contribution from $\mathrm{V}^{3+}$ and $\mathrm{V}^{2+}$, respectively ${ }^{15}$, without the presence of any new signals. In this regard, one can conclude that $\mathrm{V}^{3+}$ is the stable oxidation valence state in this $\mathrm{VN}$ electrode, whereas $\mathrm{V}^{2+}$ is the relatively stable reduction valence state. It is worth pointing out that charge compensation will occur when the amount of positive charge in active materials increases ${ }^{16}$; in other words, during the insertion of $\mathrm{Mg}^{2+}$ ions in the VN lattice. Figure $3 \mathrm{~d}$ summarizes the proportion of vanadium valence states from the ex situ V 2 p spectra. At the initial state, the concentration of $\mathrm{V}^{3+}$ and $\mathrm{V}^{2+}$ is $64 \%$ and $36 \%$, 

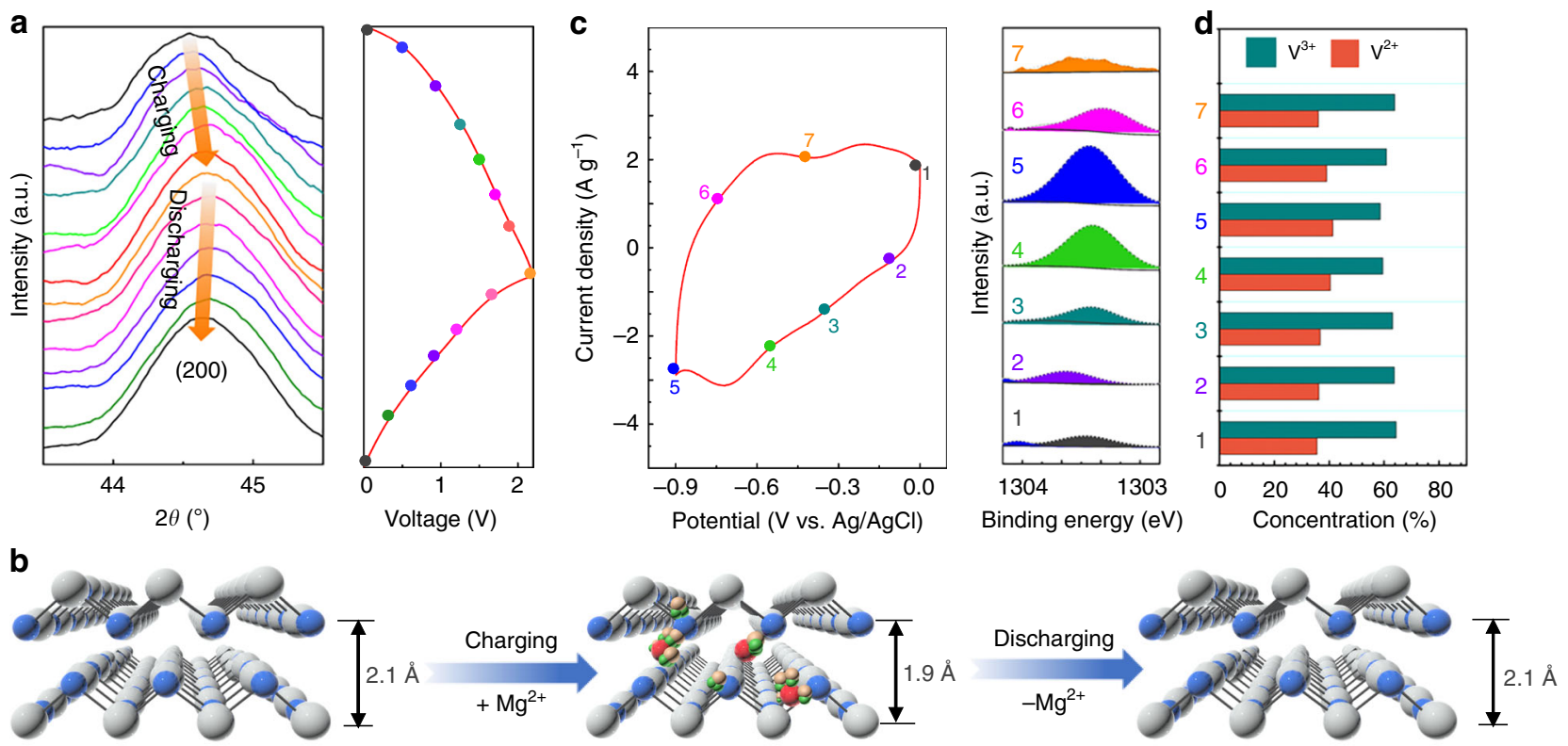

(200)

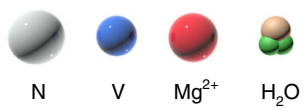

$$
\mathrm{VN}_{\mathrm{x}} \mathrm{O}_{\mathrm{y}}+\mathrm{ZMg}^{2+}+2 \mathrm{ze}^{-} \longrightarrow \mathrm{VN}_{\mathrm{x}} \mathrm{O}_{\mathrm{y}} \mathrm{Mg}_{\mathrm{z}}
$$

Fig. 3 Electrochemical reaction mechanism of $\mathrm{VN}$ in a neutral $\mathrm{MgSO}_{4}$ electrolyte. a Operando XRD patterns of $\mathrm{VN}$ during the charge/discharge process (current density: $0.1 \mathrm{~A} \mathrm{~g}^{-1}$ ). b Schematic diagram showing the contraction and expansion of the (200) crystal plane during the charge/discharge process. c Ex situ XPS Mg $1 \mathrm{~s}$ spectra at different potentials during the $\mathrm{CV}$ scan at a scan rate of $5 \mathrm{mV} \mathrm{s}^{-1}$. d Change of vanadium valence state according to XPS $V$ $2 p$ spectra

respectively (point 1 ). In turn, the ratio of $\mathrm{V}^{3+}$ decreases to $58 \%$ at the fully charged state (point 5). Upon full discharge, the proportion of $\mathrm{V}^{3+} / \mathrm{V}^{2+}$ returns back to $63 \% / 37 \%$ (point 7 ), which is in accordance with the initial state. Considering the surfacesensitive nature of the XPS technique, these results reveal that the highly reversible surface redox reactions between $\mathrm{V}^{3+} / \mathrm{V}^{2+}$ also contribute to the charge storage mechanism during the electrochemical process.

Evaluating performances of $\mathrm{Mg}$ ion quasi-solid-state ASCs. Quasi-solid-state ASCs were assembled in typical coin cell configurations, where the $\mathrm{MnO}_{2} @$ carbon $\left(\mathrm{MnO}_{2} @ \mathrm{C}\right)$ composite was employed as the positive electrode for the insertion/extraction of $\mathrm{Mg}^{2+}$ ions. The synthesized composites were subject to a wide suite of characterization tools (Supplementary Fig. 4). The threedimensional $\mathrm{MnO}_{2}$ nanoarchitecture boosts the $\mathrm{Mg}$ ion diffusion, while the conductive carbon matrix improves the electrical conductivity of the hybrid electrode. The electrochemical performances of the $\mathrm{MnO}_{2} @ \mathrm{C}$ composites were systematically measured in a three-electrode system (Supplementary Fig. 5). The electrode delivers a specific capacitance of $240 \mathrm{~F} \mathrm{~g}^{-1}$ at a scan rate of $10 \mathrm{mV} \mathrm{s}^{-1}$ with a broad potential window (from -0.3 to $1.2 \mathrm{~V}$ vs. $\mathrm{Ag} / \mathrm{AgCl}$ ), which is similar to other cation electrolyte systems $\left(\mathrm{Li}^{+}, \mathrm{Na}^{+}\right.$, and $\left.\mathrm{K}^{+}\right)$. The $\mathrm{MnO}_{2}$ electrode is likely to manifest a solid-state diffusion dominated charge storage mechanism, which is different from the capacitive charge storage behavior of the VN electrode (Supplementary Fig. 6) ${ }^{17}$.

To assemble a quasi-solid-state ASC, the starch/PAM/ $\mathrm{MgSO}_{4}$ gel was introduced as the electrolyte ${ }^{18}$. In comparison with the commonly used polyvinyl alcohol, such a PAM-based gel matrix exhibits excellent compatibility with $\mathrm{Mg}$ cations. As expected, starch molecules and acrylamide molecules physically entangle and interpenetrate with each other to form an ion conductive network with favorable water absorption ability and mechanical robustness, as demonstrated in Fig. 4a. The as-prepared gel electrolyte can return to its initial state after various deformations, such as flatting, bending and/or stretching. Figure $4 \mathrm{~b}$ presents $\mathrm{CV}$ curves for both a $\mathrm{VN}$ negative electrode and an $\mathrm{MnO}_{2}$ positive electrode at a scan rate of $10 \mathrm{mV} \mathrm{s}^{-1}$, indicating that the constructed asymmetric device can achieve a voltage window of $2.1 \mathrm{~V}$ or even larger. CV scans at different voltage ranges from 1.4 to $2.6 \mathrm{~V}$ were then carried out. Note that there is no obvious polarization even when the applied voltage is extended to $2.2 \mathrm{~V}$ (Fig. 4c, red line). Such a broad voltage range outperforms most ASCs reported recently ${ }^{19,20}$. Figure $4 d$ shows the galvanostatic charge/discharge (GCD) curves of our quasi-solid-state ASCs at different current densities from 2 to $12 \mathrm{~mA} \mathrm{~cm}^{-2}$. At $2 \mathrm{~mA} \mathrm{~cm}^{-2}$, the discharge time reaches $637 \mathrm{~s}$, corresponding to an areal capacitance of $576 \mathrm{mF} \mathrm{cm}^{-2}$, which is $79.2 \%$ of the identical device tested in a liquid electrolyte (Fig. 4e; Supplementary Fig. 7). Interestingly, once the current densities exceed $4 \mathrm{~mA} \mathrm{~cm}^{-2}$, the areal capacitance of the gel electrolyte is even higher than that of the liquid electrolyte-based system. The superior rate performance presented in gel electrolyte to that in the liquid electrolyte deserves further investigation. As such, comparative EIS profiles between the gel electrolyte and the liquid electrolyte systems before and after electrochemical tests have been collected (Fig. 4f; Supplementary Fig. 8). All these Nyquist plots have been fit according to a Randles equivalent circuit (Supplementary Table 2). It is evident that the $R_{\mathrm{s}}$ of the gel electrolyte system only exhibits a negligible increase $(0.037 \Omega)$ after electrochemical measurements, which is smaller than the $0.243 \Omega$ of the liquid electrolyte system. The much steeper line at the low-frequency range in the Nyquist plots for the gel system (especially after the electrochemical tests) also indicates enhanced ion diffusion. Such a better electrolyte ion diffusion capability is the key to achieving 
a

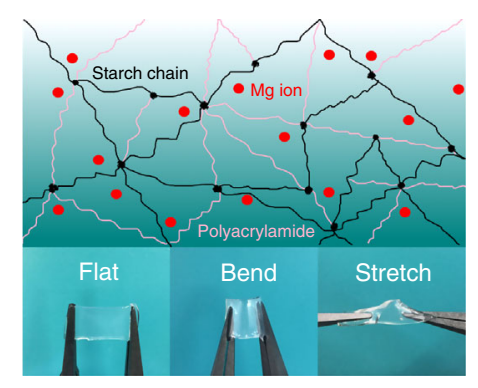

b
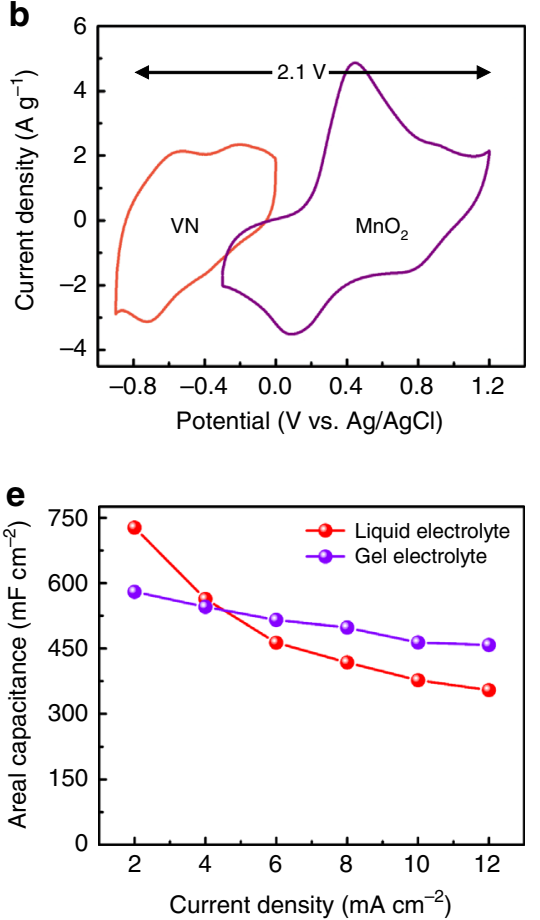

d

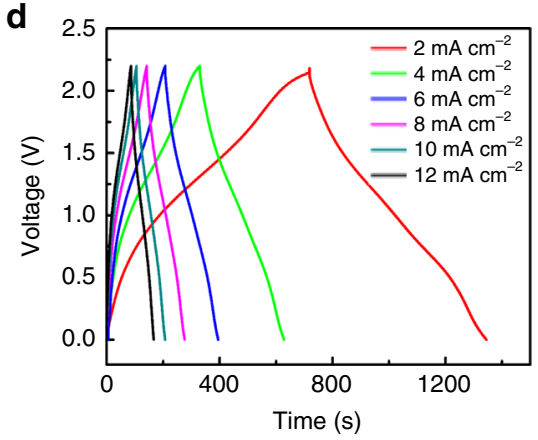

c

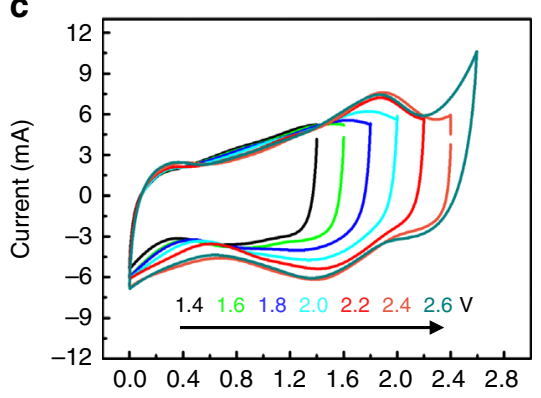

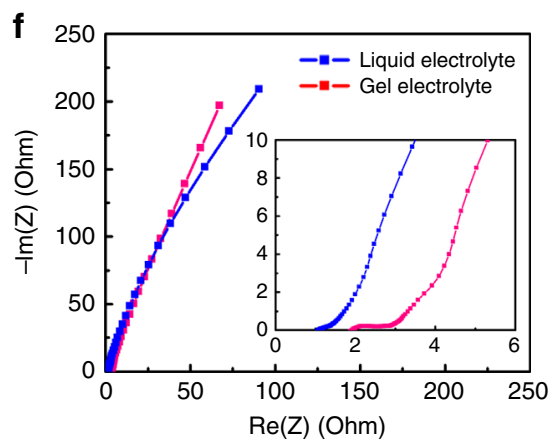
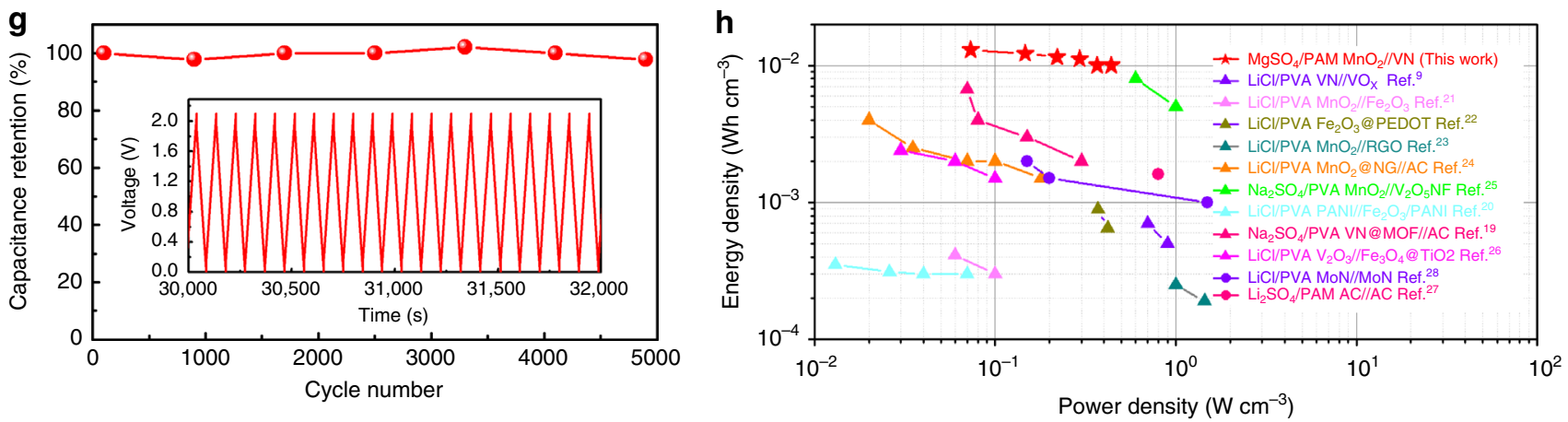

Fig. 4 Electrochemical performance of $\mathrm{Mg}$ ion quasi-solid-state ASCs. a Structural diagram of a PAM gel electrolyte and digital photos showing its mechanical robustness upon deformation. $\mathbf{b} \mathrm{CV}$ curve obtained for the $\mathrm{VN}$ and $\mathrm{MnO}_{2}$ electrodes, respectively, at different potential ranges at a scan rate of $10 \mathrm{mV} \mathrm{s}^{-1}$. c CV curves of a quasi-solid-state ASC with an increasing voltage window from 1.4 to $2.6 \mathrm{~V}$ at $10 \mathrm{mV} \mathrm{s}^{-1}$. d Galvanostatic charge/discharge curves of ASCs under different current densities. e Comparison of areal specific capacitance of a liquid electrolyte and a gel electrolyte under different current densities. $\mathbf{f}$ Nyquist plot of a liquid electrolyte/separator and a gel electrolyte. $\mathbf{g}$ Long-term cycling stability of a quasi-solid-state ASC at a charge/ discharge current density of $16 \mathrm{~mA} \mathrm{~cm}^{-2}$. h Ragone plot of our quasi-solid-state ASC devices in comparison with other recently reported quasi-solid-state ASCs in neutral electrolytes

higher rate performance. Meanwhile, exhaustive morphological and elemental characterization provides evidence that the unique porous structure, high water content ratio and tight electrolyte/ electrode interface contribute to the enhanced ion diffusion features of the gel electrolyte-based system (Supplementary Figs. 9-12). Notably, 95\% capacitance retention can be achieved at a high current density of $16 \mathrm{~mA} \mathrm{~cm}^{-2}$ after 5000 cycles, demonstrating an outstanding cycling stability of the assembled quasi-solid-state ASC (Fig. 4g). Furthermore, there is no distortion of the charge/discharge curves even for the last several cycles, as shown in the inset to Fig. $4 \mathrm{~g}$.

Figure $4 \mathrm{~h}$ presents a Ragone plot of the volumetric energy density and the power density of our quasi-solid-state ASC (VN// $\mathrm{MnO}_{2}$ ) in comparison with other recently reported quasi-solidstate supercapacitors tested in neutral gel electrolytes. Our device manifests a volumetric energy density of $13.1 \mathrm{mWh} \mathrm{cm}^{-3}$ at a power density of $72 \mathrm{~mW} \mathrm{~cm}^{-3}$. It also preserves $79 \%$ of its energy density when the power density is increased to $440 \mathrm{~mW} \mathrm{~cm}^{-3}$.
These values are markedly superior to that of state-of-the-art systems ${ }^{9}, 19-28$, including $\mathrm{VO}_{x} / / \mathrm{VN}(\mathrm{LiCl} / \mathrm{PVA})^{9}, \mathrm{MnO}_{2} @ \mathrm{NG} / /$ $\mathrm{AC}(\mathrm{LiCl} / \mathrm{PVA})^{24}, \mathrm{VN} @ \mathrm{MOF} / / \mathrm{AC} \quad\left(\mathrm{Na}_{2} \mathrm{SO}_{4} / \mathrm{PVA}\right)^{19}$, and $\mathrm{V}_{2} \mathrm{O}_{3} @ \mathrm{C} / / \mathrm{Fe}_{3} \mathrm{O}_{4} @ \mathrm{TiO}_{2}(\mathrm{LiCl} / \mathrm{PVA})^{26}$. The high energy density and excellent rate performance of our device can be mainly attributed to the significantly extended stable voltage range of the $\mathrm{Mg}$ ion system and the favorable pseudo-capacitive $\mathrm{Mg}$ ion charge storage behavior of the VN negative electrode.

Constructing flexible micro-asymmetric supercapacitors. In pursuit of portable, miniaturized and wearable energy storage devices, we next fabricated flexible micro-asymmetric supercapacitors (MASCs) consisting of $\mathrm{VN}$ and $\mathrm{MnO}_{2}$ interdigitated electrodes via screen printing ${ }^{29-32}$ (Supplementary Fig. 13). Figure $5 \mathrm{a}$ depicts the general procedure for the direct printing of MASCs, including the pre-patterning of Au films as the current collectors $^{33}$, followed by deposition of interdigitated $\mathrm{VN}$ and 
a

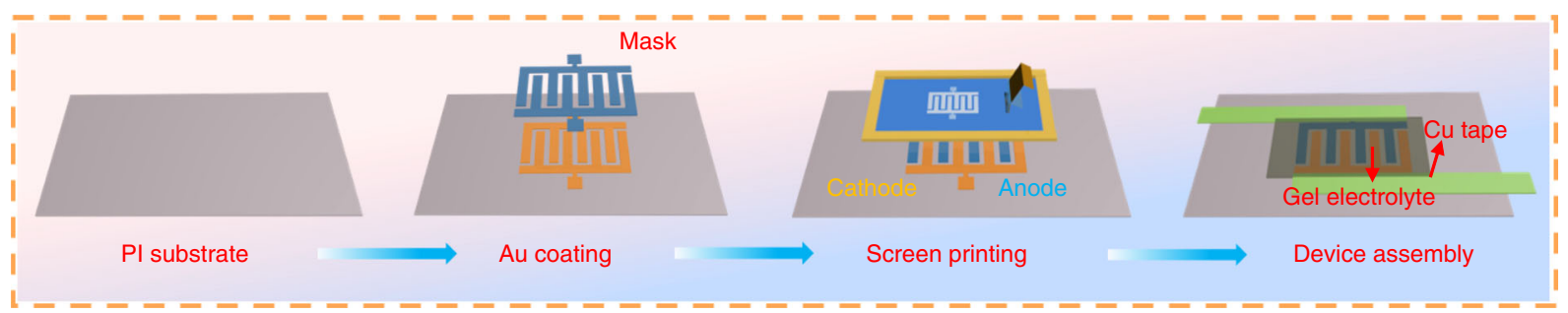

b

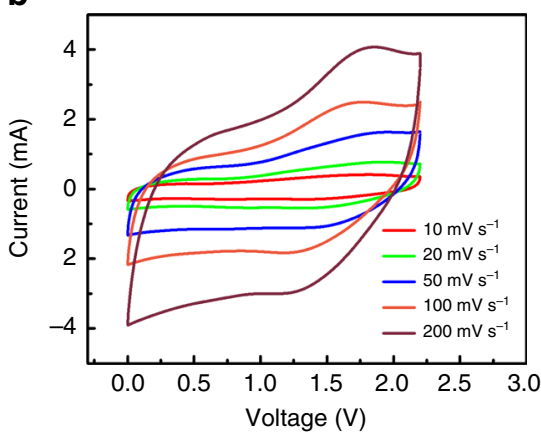

e

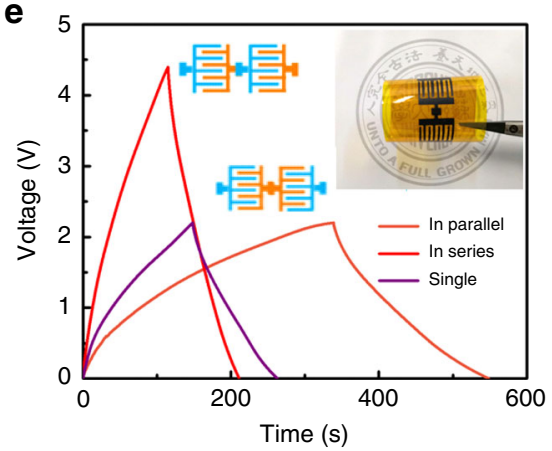

C

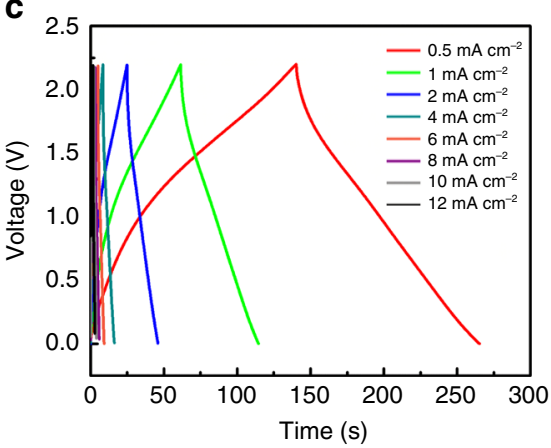

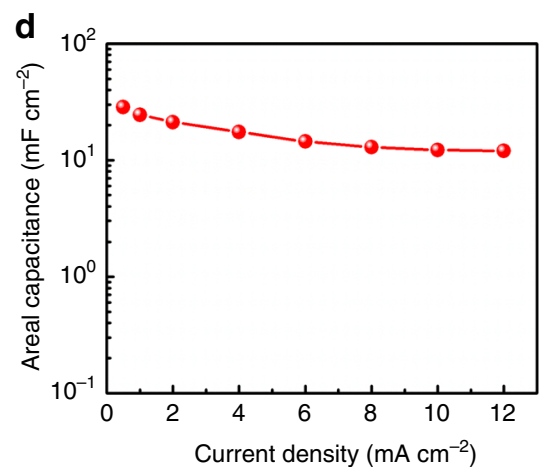

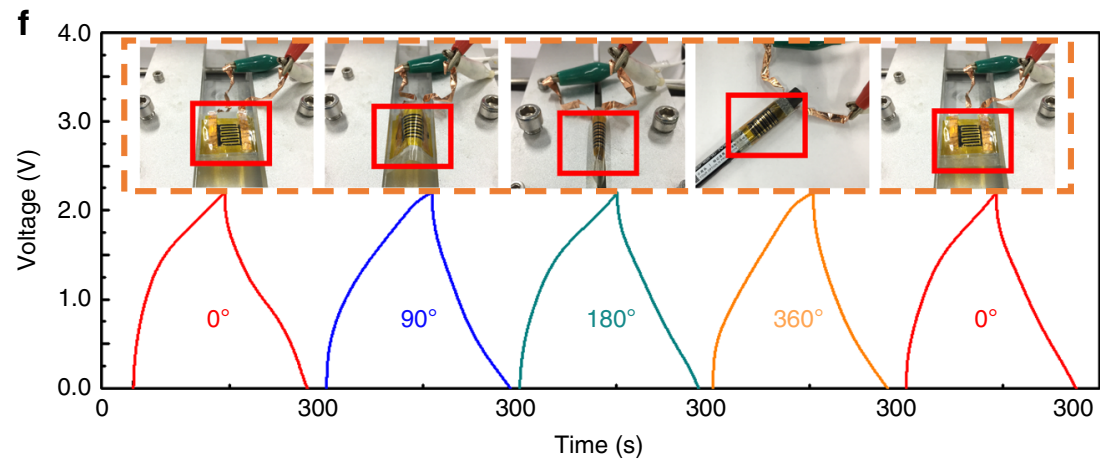

Fig. 5 Electrochemical performance of a flexible and printable quasi-solid-state MASC. a Schematic illustration of the fabrication process of a MgSO $4 / \mathrm{PAM}$ $\mathrm{VN} / / \mathrm{MnO}_{2}$ MASC. $\mathbf{b} \mathrm{CV}$ curves of a printed MASC obtained at different scan rates. c Galvanostatic charge/discharge curves tested at different current densities. d Calculated areal specific capacitance at different current densities corresponding to c. e Galvanostatic charge/discharge curves obtained at $0.5 \mathrm{~mA} \mathrm{~cm}^{-2}$ of single, series and parallel connections of two MASCs. $\mathbf{f}$ Galvanostatic charge/discharge curves tested at $0.5 \mathrm{~mA} \mathrm{~cm}{ }^{-2}$ under different bending angles

$\mathrm{MnO}_{2}$ electrodes, and the application of the $\mathrm{PAM}-\mathrm{MgSO}_{4}$ gel electrolyte (with detailed dimensions of the screen-printing pattern shown in Supplementary Fig. 14). The electrochemical performances of the as-constructed $\mathrm{VN} / / \mathrm{MnO}_{2}$ MASCs were characterized by $\mathrm{CV}$ and GCD measurements. Figure $5 \mathrm{~b}$ shows the CV profiles of the MASC at different scan rates. Note that the open circuit voltage reaches a remarkable $2.2 \mathrm{~V}$, exceeding most of the recently reported in-plane micro-supercapacitors and ASCs. A couple of redox peaks can still be detected, in good agreement with the foregoing results of the quasi-solid-state asymmetric SC in a coin cell configuration. The CV shape is well preserved from 10 to $200 \mathrm{mV} \mathrm{s}^{-1}$, suggesting excellent rate capability of the device. Figure $5 c$ displays the GCD curves at different current densities from 0.5 to $12 \mathrm{~mA} \mathrm{~cm}^{-2}$, showing obvious triangular shapes. As such, our printed MASC delivers an areal capacitance of $28.5 \mathrm{mF} \mathrm{cm}^{-2}$ at $0.5 \mathrm{~mA} \mathrm{~cm}^{-2}$, while $42 \%$ of this capacitance remains upon testing at $12 \mathrm{~mA} \mathrm{~cm}^{-2}$, as shown in Fig. 5d. The thus-derived MASCs display a slow self-discharge process (Supplementary Fig. 15) and a stable long cycle performance (a capacitance retention of $90 \%$ after 8000 cycles; see Supplementary Fig. 16). In addition, the Ragone plot drawn in Supplementary Fig. 17 demonstrates that our printed MASCs harvest an energy density of $19.13 \mu \mathrm{Wh} \mathrm{cm}^{-2}$ at a power density of $0.55 \mathrm{~mW} \mathrm{~cm}^{-2}$, outperforming those of recently reported inplane micro-supercapacitors (see Supplementary Table 3 for detailed information).

To efficiently boost the operating voltage and capacitance output of a single device, MASCs could be easily connected in series or in parallel by optimizing the printing process. Figure $5 \mathrm{e}$ presents the GCD curves of single, series and parallel MASCs. In this regard, a series connection enables the extension of the output voltage to $4.4 \mathrm{~V}$ (double the $2.2 \mathrm{~V}$ for a single device). Meanwhile, the capacitance can be readily doubled by adopting a parallel connection, demonstrating advanced modulation for device integration ${ }^{33}$. To further evaluate the mechanical robustness of our MASC targeting practical wearable applications, we carried out GCD measurements under bending angles of $0^{\circ}, 90^{\circ}$, $180^{\circ}$, and $360^{\circ}$ (Fig. 5f, and inset). Notably, the shapes of the GCD curves with different bending angles only change slightly, with almost $100 \%$ of the initial capacitance retained on bending at $360^{\circ}$, thus demonstrating excellent mechanical flexibility. Such printed MASCs with their excellent mechanical properties are thus conducive to multi-field integration with solar cell systems. 

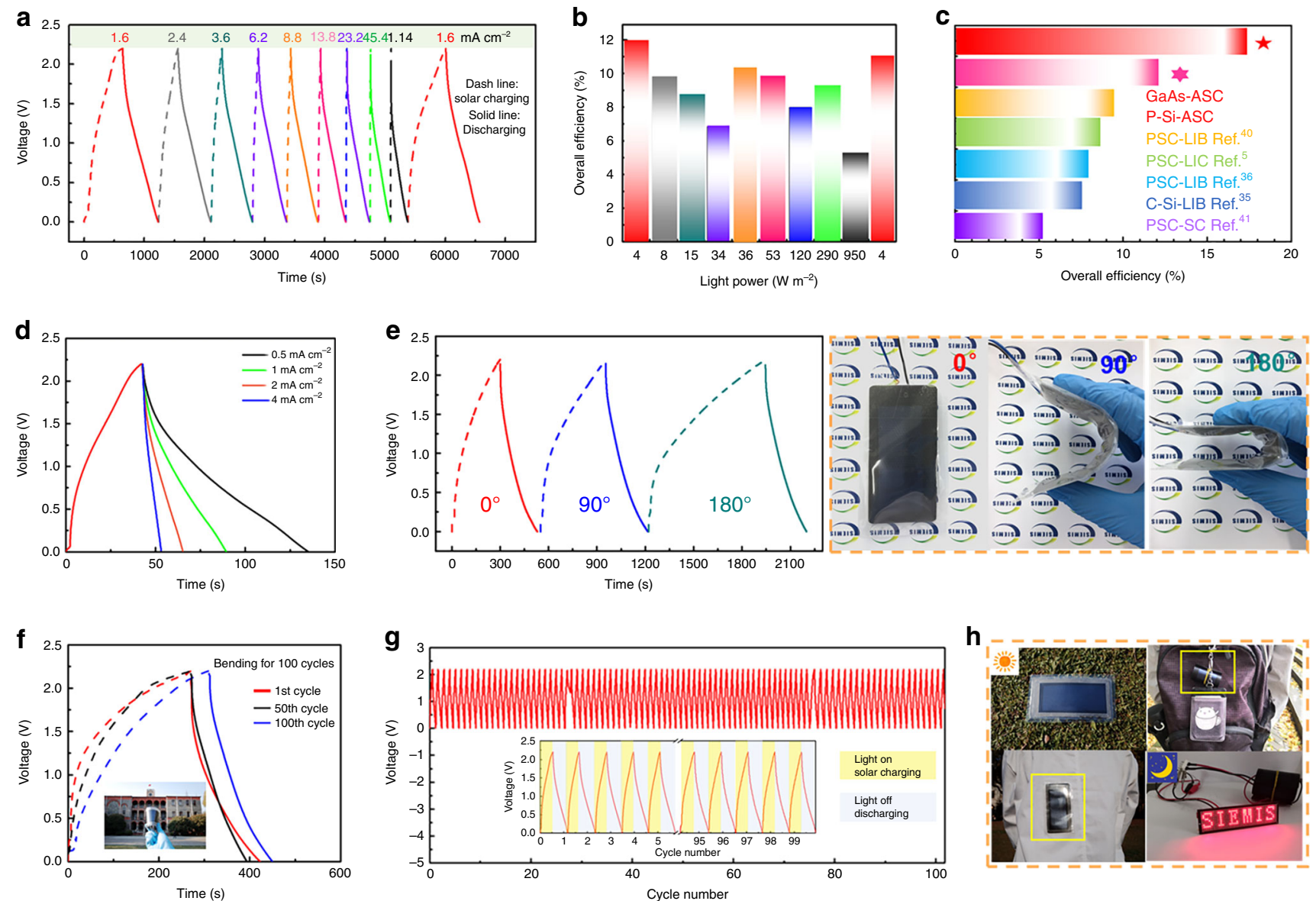

Fig. 6 Electrochemical performance of as-constructed solar-charging integrated units. a Solar-charging/discharging curves at different light intensities and the same discharge current density of $1 \mathrm{~mA} \mathrm{~cm}^{-2}$. b Calculated $\eta_{\text {overall }}$ at different light intensities corresponding to $\mathbf{a}$. $\mathbf{c}$ Comparison of $\eta_{\text {overall }}$ with a recently reported solar-charging integrated energy system. d Voltage-time profiles of our flexible solar-charging integrated units. e Solar-charging/ discharging curves at different bending angles (left panel), with digital photos (right panel) showing bending conditions. $\mathbf{f}$ Durability test of a flexible solarcharging integrated unit for 100 cycles. $\mathbf{g}$ Long cycling stability of a flexible solar-charging integrated unit. $\mathbf{h}$ Demonstration of wearable scenarios using our solar-charging integrated units

Integrating flexible solar-charging self-powered units. The rapid development of wearable smart electronics has led to a huge demand for flexible, safe, and long-life energy sources ${ }^{34}$. The printed MASCs as demonstrated above could serve as viable energy storage devices, but might still not meet the self-powered requirements with no external charging supply, especially for wearable applications. In this respect, integration with an energyharvesting component, such as a solar cell, is a feasible solution to both capture and energy storage within a single device. We started by evaluating our flexible $\mathrm{VN} / / \mathrm{MnO}_{2}$ ASC within a solarcharging integration system. To achieve this, a low-cost polycrystalline Si solar cell was employed as the PV module (Supplementary Fig. 18a, b) and an as-assembled quasi-solid-state ASC was used as the energy storage module. Figure 6a displays the solar-charging/discharging profiles of the integrated device under varied light intensities with the same discharge current density $\left(1 \mathrm{~mA} \mathrm{~cm}^{-2}\right)$. The output current density of the solar cell corresponding to the light intensity is shown in Supplementary Fig. 18c. When the light intensity was increased from 4 to $950 \mathrm{~W}$ $\mathrm{cm}^{-2}$, the output current density responsively increased from 1.6 to $114 \mathrm{~mA} \mathrm{~cm}^{-2}$. Such an abrupt increase in light intensity (current) could significantly shorten the duration of solarcharging (e.g. to $3 \mathrm{~s}$ ). In addition, the discharge time is correspondingly reduced, which can be attributed to an increased IR drop at the large current densities. It is worth-noting that the discharge behavior can still return to the initial state upon dialing the light intensity back to $4 \mathrm{~W} \mathrm{~cm}^{-2}$, indicative of excellent rate capability. In other words, our ASC demonstrates the ability to withstand large currents (e.g., $114 \mathrm{~mA} \mathrm{~cm}^{-2}$ ), outperforming emerging energy storage counterparts (such as lithium ion batteries, $\mathrm{LIBs}^{35,36}$, and capacitors, $\left.\mathrm{LICs}^{5}\right)$. The overall efficiency for energy conversion and storage $\left(\eta_{\text {overall }}\right)$ has been calculated at different light intensities, as summarized in Fig. 6b. The highest $\eta_{\text {overall }}$ is achieved at a light intensity of $4 \mathrm{~W} \mathrm{~cm}^{-2}$ (corresponding to typical indoor-ambient lighting conditions), reaching a remarkable $11.95 \%$. Such a high overall efficiency and excellent indoor light performance can be attributed to the high current tolerance and high-energy storage efficiency ( $\left.\eta_{\text {storage }}\right)$ of our ASC, where the $\eta_{\text {storage }}$ is calculated to be $\sim 80 \%$. To further verify the superiority of our solar-charging system, a GaAs-ASC integrated device was fabricated by combining GaAs solar cells with assembled ASCs, demonstrating a record high $\eta_{\text {overall }}$ of $17.57 \%$ under $1000 \mathrm{~W} \mathrm{~m}^{-2}$ (Supplementary Fig. 19). Such a remarkable overall efficiency can be attributed to the high conversion efficiency of the GaAs solar cell $(25.88 \%)$ and the high-energy storage efficiency of the ASC (67.90\%). Figure 6c draws comparisons of $\eta_{\text {overall }}$ between our integrated unit and state-of-the-art solarcharging systems. It is obvious that the $\eta_{\text {overall }}$ of our Si solar cell/ ASC and GaAs solar cell/ASC devices outperform the other integrated systems, such as a Si solar cell integrated LIB (c-Si-LIB, 
7.61\%) and a perovskite solar cell combined with a LIC (PSC-LIC, $8.41 \%$ ). Detailed comparisons of the key parameters (overall efficiency, output voltage and endurance current) between the current work and other reported studies in the field of solarcharging self-powered systems is provided in Supplementary Table 4 .

We then considered the practical uses of our system by assembling a flexible solar-charging integrated unit according to the configuration depicted in Fig. 1a. Notably, a flexible amorphous Si solar cell functioned as the PV module (Supplementary Fig. 20a, b). The VN//MnO 2 MASC was printed directly on the bottom of the solar cell, which is buffered by a polyimide (PI) layer. Figure 6d illustrates the solar-charging/discharging curves of our flexible integrated device. Under the same solarcharging condition of $4 \mathrm{~W} \mathrm{~cm}^{-2}$, it exhibits a favorable rate performance. The $\eta_{\text {overall }}$ of such a flexible system reaches $5.2 \%$ (Supplementary Fig. 20c). Despite being not as high as our rigid integrated unit, this is still superior to most reported flexible photo-charging self-powered systems , $^{47-41}$ (see Supplementary Table 5). To envisage realistic wearable applications, we further evaluated the mechanical stability of the integrated solar-charging self-powered units. Figure 6e shows the solar-charging $\left(4 \mathrm{~W} \mathrm{~cm}^{-2}\right) /$ discharging $\left(1 \mathrm{~mA} \mathrm{~cm}^{-2}\right)$ profiles under bending angles of $0^{\circ}, 90^{\circ}$, and $180^{\circ}$ (as displayed by the digital photos). The observation of increased solar-charging duration as a function of bending can be mainly attributed to the decrease in the effective area of illumination of a bent solar cell. Under this circumstance, the discharge energy, indicated by the discharging time, remains constant, demonstrating good flexibility of our self-powered unit. A mechanical durability test was also carried out by repeatedly bending the integrated device at $90^{\circ}$ for 100 cycles (Fig. 6f,inset). The capacitance retention reached $94 \%$ and $80 \%$ after 10 and 100 bending cycles, respectively. In further tests, various flexible conditions were implemented to verify the mechanical robustness of our devices (Supplementary Fig. 21). Before and after folding, rolling, and waving deformations, the integrated unit exhibited a capacitance retention of $97.50 \%, 85.22 \%$, and $93.04 \%$, respectively. All these provide evidence for the good flexibility of our self-powered unit for practical applications.

Figure $6 \mathrm{~g}$ further presents the photo-charging/discharging cycling performance tested at a light intensity of $4 \mathrm{~W} \mathrm{~cm}-2$ and a discharge current density of $1 \mathrm{~mA} \mathrm{~cm}^{-2}$, with the inset showing the first 10 cycles and last 10 cycles of photo-charging/ discharging curves. Remarkably, our integrated unit maintained outstanding cycling stability with a surprisingly high capacitance retention of $98.7 \%$ after 100 cycles, thus demonstrating excellent robustness and mechanical stability. It is anticipated that our integrated solar-charging self-powered units with good flexibility, long cycle life, and high safety will be viable for many wearable scenarios. Figure $6 \mathrm{~h}$ shows a proof-of-concept demonstration. The integrated unit can be fully charged when exposed to either natural sunlight or outdoor lighting (i.e., during the daytime). The flexible and even rollable feature of such a power unit enables the direct wearing on clothes or application to bags as an efficient self-powered energy source. The energy stored in the solarcharged MASC can be ultimately utilized to power a lightemitting-diode panel, especially for indoor use during night time.

\section{Discussion}

In summary, a highly flexible, safe, and durable solar-charging self-powered integrated unit has been developed. By synergistically combining an in-plane asymmetric printing technology with a multivalent ion electrochemical energy storage technology, the thus-derived integrated units show outstanding photo-charging cyclic stability (up to $98.7 \%$ capacitance retention after 100 cycles), with tolerance for a wide variation in current (from 1.6 to $114 \mathrm{~mA} \mathrm{~cm}^{-2}$ ), and favorable energy management for wearable devices. Moreover, the pseudo-capacitive intercalation/de-intercalation reaction mechanism of $\mathrm{Mg}^{2+}$ ions in $\mathrm{VN}$ electrodes has been elucidated using operando XRD and ex situ XPS, explaining both high energy density $\left(13.1 \mathrm{mWh} \mathrm{cm}^{-3}\right)$ and high power density $\left(440 \mathrm{~mW} \mathrm{~cm}^{-3}\right)$ of the $\mathrm{VN} / / \mathrm{MnO}_{2}$ ASCs. Such ASCs based on multivalent neutral ion electrolytes offer new insights into the design of high-energy, long-life, and safe energy sources toward the ultimate goal of creating light weight and wearable smart electronics.

\section{Methods}

Preparation of $\mathbf{V N}$ and $\mathbf{M n O}_{\mathbf{2}} @ \mathbf{C}$ electrode materials. Ammonium metavanadate was dissolved in $135 \mathrm{~mL}$ of deionized water and $15 \mathrm{~mL}$ of ethanol by stirring, followed by the addition of hydrochloric acid $\left(1 \mathrm{~mol} \mathrm{~L}^{-1}\right)$ to adjust the $\mathrm{pH}$ value of the solution to 2.0. The mixture was then transferred into a Teflon-lined autoclave and kept at $180{ }^{\circ} \mathrm{C}$ for $24 \mathrm{~h}$. After cooling down to room temperature, a nanobelt-like $\mathrm{VO}_{2}$ product was obtained upon washing and drying. Finally, $\mathrm{VN}$ nanowires were produced by annealing the above-synthesized $\mathrm{VO}_{2}$ in pure $\mathrm{NH}_{3}$ at $600{ }^{\circ} \mathrm{C}$ for $3 \mathrm{~h}$. As for the $\mathrm{MnO}_{2} @ \mathrm{C}$ synthesis, $2 \mathrm{~mL}$ of an aqueous $\mathrm{GO}$ suspension $\left(5 \mathrm{mg} \mathrm{mL}^{-1}\right)$ was added into $58 \mathrm{~mL}$ of deionized water, followed by the addition of $\mathrm{KMnO}_{4}(316 \mathrm{mg})$ and urea $(1 \mathrm{~g})$. After stirring for $20 \mathrm{~min}$, the above solution was transferred into a Teflon-lined autoclave and kept at $120^{\circ} \mathrm{C}$ for $12 \mathrm{~h}$. Nanoflower-like $\mathrm{MnO}_{2} @ \mathrm{C}$ was readily obtained after washing and drying.

Preparation of $\mathbf{M g S O}_{\mathbf{4}}$-PAM gel electrolyte. Three grams of starch was dissolved into $30 \mathrm{~mL}$ of deionized water by vigorously stirring at $100^{\circ} \mathrm{C}$ for $1 \mathrm{~h}$. After cooling, $5 \mathrm{~g}$ of acrylamide monomer, $25 \mathrm{mg}$ of $\mathrm{NH}_{4} \mathrm{~S}_{2} \mathrm{O}_{8}$, and $3 \mathrm{mg}$ of $N, N^{\prime}$-methylenebisacrylamide were added. The solution was stirred at room temperature for $2 \mathrm{~h}$, followed by the elimination of surface bubbles under vacuum. The solution was then poured into a mold of a specific thickness and heated at $80^{\circ} \mathrm{C}$ for $1 \mathrm{~h}$. The asprepared PAM gel was then immersed into $1.0 \mathrm{M} \mathrm{MgSO}_{4}$ electrolyte for more than $24 \mathrm{~h}$ to reach the ion balance point.

Assembly of quasi-solid-state ASCs. Mg ion quasi-solid-state ASCs were assembled using a typical coin cell structure. The negative electrode was prepared by casting onto Ti mesh a slurry containing the active material $\mathrm{VN}$, conductive carbon (Super P), and binder (PVDF) in a mass ratio of $8: 1: 1$. The mass loading was adjusted to $5-6 \mathrm{mg} \mathrm{cm}^{-2}$. The $\mathrm{MnO}_{2} @ \mathrm{C}$ positive electrode was fabricated using a similar method, with the mass ratio at 7.5:2:0.5. The $\mathrm{MgSO}_{4}-\mathrm{PAM}$ gel was employed as the electrolyte. The optimized mass ratio of the positive and negative electrode was 1:2 (Supplementary Fig. 22). The thickness of the negative electrode, the positive electrode, and the gel electrolyte were 50,50 , and $200 \mu \mathrm{m}$, respectively. Moreover, a liquid electrolyte-based ASC was assembled as a control by using glass fiber as the separator with a liquid electrolyte.

The capacitance is calculated using the following equations:

According to the $\mathrm{CV}$ curves

$$
C=\frac{1}{\nu * \Delta V} \int_{V 1}^{V 2} I(V) \mathrm{d} V
$$

In the three-electrode system, $C$ is the capacitance $(\mathrm{F}), v$ is scan rate $\left(\mathrm{V} \mathrm{s}^{-1}\right), I$ is the current response (A), $V 1(V 2)$ is the starting and ending voltage (V), and $\Delta V$ is the voltage window $(\mathrm{V})$. For the single electrode, the specific capacitance is calculated according the following equation:

$$
C_{m}=\frac{C}{2 m},
$$

where $C_{m}$ is the mass specific capacitance $\left(\mathrm{Fg}^{-1}\right), C$ is the capacitance (F), and $m$ is the mass of active material (g; without the consideration of binders and conductive agents).

In the two-electrode system, the electrochemical performance is calculated according to the GCD curves

$$
C=\frac{I t}{\Delta V},
$$

where $C$ is the capacitance (F), $I$ is the discharging current (A), $t$ is the discharging time (s), and $\Delta V$ is the voltage window $(\mathrm{V})$. For the device, the specific capacitance is calculated according the following equation:

$$
C_{m}(s)=\frac{C}{m(s)},
$$

where $C_{m}(\mathrm{~s})$ is the mass or area specific capacitance $\left(\mathrm{F} \mathrm{g}^{-1}\right.$ or $\left.\mathrm{F} \mathrm{cm}^{-2}\right), m$ is the total mass of positive and negative active material $(\mathrm{g}), s$ is the area of positive or 
negative electrode $\left(\mathrm{cm}^{-2}\right.$, the area of positive and negative electrode is the same), and $C$ is the capacitance $(\mathrm{F})$.

The energy density $(E)$ and power density $(P)$ can be derived according to the following equations:

$$
E_{m}=\frac{1}{2 \times 3.6} C_{m} \times V^{2},
$$

where $E_{m}$ is the mass energy density ( $\mathrm{Wh} \mathrm{kg}^{-1}$ ), $C_{m}$ is the mass specific capacitance $\left(\mathrm{Fg}^{-1}\right)$, and $V$ is the voltage $(\mathrm{V})$.

$$
E_{v}=\frac{1}{2 \times 3600} C_{v} * V^{2},
$$

where $E_{v}$ is volume energy density $\left(\mathrm{Wh} \mathrm{cm}^{-3}\right), C_{v}$ is the volume specific capacitance $\left(\mathrm{F} \mathrm{cm}^{-3}\right.$, the volume is the product of electrode area and thickness, which includes the thickness of the positive electrode, the gel electrolyte, and the negative electrode), and $V$ is the voltage (V).

As for the power density, the calculated equation is

$$
P=\frac{E}{t},
$$

where $P$ is the power density $\left(\mathrm{W} \mathrm{kg}^{-1}\right.$ or $\left.\mathrm{W} \mathrm{cm}{ }^{-3}\right), E$ is the energy density $\left(\mathrm{Wh} \mathrm{kg}^{-1}\right.$ or $\mathrm{Wh}_{\mathrm{cm}}^{-3}$ ), and $t$ is the discharging time (h).

Construction of flexible MASCs via printing. Flexible MASCs were constructed via a sequential screen-printing method. First, the PI substrate was treated with an $\mathrm{O}_{2}$ plasma. The as-treated substrate was subjected to a DC sputtering of gold for $15 \mathrm{~min}$, where a printing mask was used to outline the gold deposition. Next, the VN electrode was printed with a slurry containing $80 \% \mathrm{VN}, 10 \%$ conductive carbon black and $10 \%$ LA132. After drying, a second printing was applied to create the $\mathrm{MnO}_{2}$ electrode (75\% $\mathrm{MnO}_{2} @ \mathrm{C}, 15 \%$ Super P, and 10\% LA132). A gel electrolyte was then coated over the patterned electrodes, with copper tape employed as the current collectors. Finally, the entire device was wrapped in a commercial thermoplastic PET film (see Supplementary Note 2 for the printing details). The encapsulation process is described as follows: First, the $\mathrm{Cu}$ conductive tape was pasted over the lead, the gel electrolyte was then coated on the printed pattern. Second, the micro-supercapacitor was placed between two plastic films and sealed by thermoplastic sealing. Finally, the tip of the lead was fixed using an AB glue (Supplementary Fig. 23).

Assembly of flexible solar-charging integrated units. To assemble the flexible self-powered units, flexible commercial amorphous Si solar cells were used as the energy-harvesting module. To avoid the non-smooth surface of the flexible solar cell, acrylic double-sided tape was first pasted onto the backside of the solar cell. Then, the cleaned PI substrate was attached to the other side of the acrylic tape, which was used for the printed substrate of the MASCs. After that, the MASC was fabricated by screen-printing. The gel electrolyte was then coated on the micropattern and the MASC was sealed using plastic film. Finally, the self-powered unit was packaged using the same plastic film (see Supplementary Fig. 24). To reach the matched open circuit voltage, two solar cells were connected in series to power a MASC module.

The overall efficiency of energy conversion and storage $\left(\eta_{\text {overall }}\right)$ can be calculated according to the following equation:

$$
\eta_{\text {overall }}=\frac{E}{P \times S \times t} \times 100 \%,
$$

where $E, P, S$, and $t$ are the discharge energy after solar-charging (Wh), the light intensity $\left(\mathrm{W} \mathrm{m}^{-2}\right)$, the effective area of solar cell $\left(\mathrm{m}^{2}\right)$, and the duration of solarcharging $(\mathrm{h})$, respectively.

Characterization. The morphologies of samples were characterized by a Hitachi SU8010 scanning electron microscopy. STEM and HRTEM images were obtained on a Cs-corrected FEI Titan transmission electron microscopy operated at $300 \mathrm{kV}$. XPS spectra (including ex situ XPS analysis) were collected using an Escalab 250Xi Spectrophotometer using a monochromatic Al-Ka X-ray source. XRD measurements (including operando XRD) were performed at a Bruker D8 Advance Diffractometer using $\mathrm{Cu}-\mathrm{Ka}$ radiation $(\lambda=1.5406 \AA)$. All the electrochemical data were measured by a CHI760E workstation $(\mathrm{CH}$ Instruments, USA). The three-electrode tests (CV, LSV, GCD) were performed utilizing an $\mathrm{Ag} / \mathrm{AgCl}$ reference electrode and a graphite rod counter electrode.

\section{Data availability}

The data supporting the findings of this work are available within the article and its Supplementary Information files. All other relevant data supporting the findings of this study are available from the corresponding author on request.

Received: 21 June 2019; Accepted: 23 September 2019; Published online: 29 October 2019

\section{References}

1. Park, S. et al. Self-powered ultra-flexible electronics via nano-gratingpatterned organic photovoltaics. Nature 561, 516-521 (2018).

2. $\mathrm{Li}, \mathrm{C}$. et al. Wearable energy-smart ribbons for synchronous energy harvest and storage. Nat. Commun. 7, 13319 (2016).

3. Shao, Y. et al. Design and mechanisms of asymmetric supercapacitors. Chem. Rev. 118, 9233-9280 (2018).

4. Zhang, F. et al. Highly flexible and scalable photo-rechargeable power unit based on symmetrical nanotube arrays. Nano Energy 46, 168-175 (2018).

5. Li, C. et al. Flexible perovskite solar cell-driven photo-rechargeable lithiumion capacitor for self-powered wearable strain sensors. Nano Energy $\mathbf{6 0}$, 247-256 (2019)

6. Dong, L. et al. Multivalent metal ion hybrid capacitors: a review with a focus on zinc-ion hybrid capacitors. J. Mater. Chem. A 7, 13810-13832 (2019).

7. Li, K. et al. Aluminum-ion-intercalation supercapacitors with ultrahigh areal capacitance and highly enhanced cycling stability: power supply for flexible electrochromic devices. Small 13, 1700380 (2017).

8. Song, Y. et al. Synchronous immobilization and conversion of polysulfides on a $\mathrm{VO}_{2}-\mathrm{VN}$ binary host targeting high sulfur load Li-S batteries. Energy Environ. Sci. 11, 2620-2630 (2018).

9. $\mathrm{Lu}, \mathrm{X}$. et al. High energy density asymmetric quasi-solid-state supercapacitor based on porous vanadium nitride nanowire anode. Nano. Lett. 13, 2628-2633 (2013).

10. Yuan, C. et al. Investigation of the intercalation of polyvalent cations $\left(\mathrm{Mg}^{2+}\right.$, $\mathrm{Zn}^{2+}$ ) into $\lambda-\mathrm{MnO}_{2}$ for rechargeable aqueous battery. Electrochim. Acta 116, 404-412 (2014).

11. Augustyn, V. et al. High-rate electrochemical energy storage through $\mathrm{Li}^{+}$ intercalation pseudocapacitance. Nat. Mater. 12, 518-522 (2013).

12. Wang., J. et al. Pseudocapacitive contributions to electrochemical energy storage in $\mathrm{TiO}_{2}$ (anatase) nanoparticles. J. Phys. Chem. C. 111, 14925-14931 (2007).

13. Li, K. et al. Lattice-contraction triggered synchronous electrochromic actuator. Nat. Commun. 9, 4798 (2018)

14. Song, J. et al. Activation of a $\mathrm{MnO}_{2}$ cathode by water-stimulated $\mathrm{Mg}^{2+}$ insertion for a magnesium ion battery. Phys. Chem. Chem. Phys. 17, 5256-5264 (2015).

15. Song, Y. et al. Enhanced sulfur redox and polysulfide regulation via porous VN-modified separator for Li-S batteries. ACS Appl. Mater. Interfaces 11, 5687-5694 (2019).

16. Jia, Z. et al. Vertically aligned $\alpha-\mathrm{MnO}_{2}$ nanosheets on carbon nanotubes as cathodic materials for aqueous rechargeable magnesium ion battery. Ionics $\mathbf{2 4}$, 3483-3491 (2018).

17. Sun, X. et al. Investigation of the mechanism of $\mathrm{Mg}$ insertion in birnessite in nonaqueous and aqueous rechargeable Mg-ion batteries. Chem. Mater. 28, 534-542 (2016).

18. $\mathrm{Li}, \mathrm{H}$. et al. $\mathrm{MoS}_{2}$ nanosheets with expanded interlayer spacing for rechargeable aqueous Zn-ion batteries. Energy Storage Mater. 19, 94-101 (2019).

19. Yan, Y. et al. Facile synthesis of vanadium metal-organic frameworks for highperformance supercapacitors. Small 14, 1801815 (2018).

20. Yang, Z. et al. Hierarchical nanostructured $a-\mathrm{Fe}_{2} \mathrm{O}_{3} /$ polyaniline anodes for high performance supercapacitors. Electrochim. Acta 269, 21-29 (2018).

21. Lu, X. et al. Oxygen-deficient hematite nanorods as high-performance and novel negative electrodes for flexible asymmetric supercapacitors. Adv. Mater. 26, 3148-3155 (2014).

22. Zeng, Y. et al. Advanced Ti-doped $\mathrm{Fe}_{2} \mathrm{O}_{3} @$ PEDOT core/shell anode for highenergy asymmetric supercapacitors. Adv. Energy Mater. 5, 1402176 (2015).

23. Zhai, T. et al. Oxygen vacancies enhancing capacitive properties of $\mathrm{MnO}_{2}$ nanorods for wearable asymmetric supercapacitors. Nano Energy 8, 255-263 (2014).

24. Liu, Y. et al. Layered- $\mathrm{MnO}_{2}$ nanosheet grown on nitrogen-doped graphene template as a composite cathode for flexible solid-state asymmetric supercapacitor. ACS Appl. Mater. Interfaces 8, 5251-5260 (2016).

25. Huang, $\mathrm{Z}$. H. et al. High mass loading $\mathrm{MnO}_{2}$ with hierarchical nanostructures for supercapacitors. ACS Nano 12, 3557-3567 (2018).

26. Li, R. et al. Conformal multifunctional titania shell on iron oxide nanorod conversion electrode enables high stability exceeding 30000 cycles in aqueous electrolyte. Adv. Funct. Mater. 28, 1800497 (2018).

27. Genovese, M. et al. Ultrathin all-solid-state supercapacitor devices based on chitosan activated carbon electrodes and polymer electrolytes. Electrochim. Acta 273, 392-401 (2018).

28. Xiao, X. et al. Salt-templated synthesis of $2 \mathrm{D}$ metallic $\mathrm{MoN}$ and other nitrides. ACS Nano 11, 2180-2186 (2017).

29. Jost, K. et al. Knitted and screen printed carbon-fiber supercapacitors for applications in wearable electronics. Energy Environ. Sci. 6, 2698-2705 (2013).

30. Zhang, Y. Z. et al. Printed supercapacitors: materials, printing and applications. Chem. Soc. Rev. 48, 3229-3264 (2019). 
31. Li, D. et al. A simple strategy towards highly conductive silver-nanowire inks for screen-printed flexible transparent conductive films and wearable energystorage devices. Adv. Mater. Technol. 4, 2698-2705 (2019).

32. Zhang, Y. Z. et al. A simple approach to boost capacitance: flexible supercapacitors based on manganese oxides@MOFs via chemically induced in situ self-transformation. Adv. Mater. 28, 5242-5248 (2016).

33. Guo, R. et al. In-plane micro-supercapacitors for an integrated device on one piece of paper. Adv. Funct. Mater. 27, 1702394 (2017).

34. Zhang et al. MXenes stretch hydrogel sensor performance to new limits. Sci. Adv. 4, eaat0098 (2018).

35. Um, H.-D. et al. Monolithically integrated, photo-rechargeable portable power sources based on miniaturized Si solar cells and printed solid-state lithium-ion batteries. Energy Environ. Sci. 10, 931-940 (2017).

36. $\mathrm{Xu}$, J. et al. Efficiently photo-charging lithium-ion battery by perovskite solar cell. Nat. Commun. 6, 8103 (2015).

37. Chai, Z. et al. Tailorable and wearable textile devices for solar energy harvesting and simultaneous storage. ACS Nano 10, 9201-9207 (2016).

38. Dong, P. et al. A flexible solar cell/supercapacitor integrated energy device. Nano Energy 42, 181-186 (2017).

39. Lechêne, B. P. et al. Organic solar cells and fully printed super-capacitors optimized for indoor light energy harvesting. Nano Energy 26, 631-640 (2016).

40. Gurung, A. et al. Highly efficient perovskite solar cell photocharging of lithium ion battery using DC-DC booster. Adv. Energy Mater. 7, 1602105 (2017).

41. Liang, J. et al. An all-inorganic perovskite solar capacitor for efficient and stable spontaneous photocharging. Nano Energy 52, 239-245 (2018).

\section{Acknowledgements}

This work was financially supported by the National Natural Science Foundation of China (51702225), National Key Research and Development Program

(2016YFA0200103), and Natural Science Foundation of Jiangsu Province (BK20170336). The authors also acknowledge support from the Suzhou Key Laboratory for Advanced Carbon Materials and Wearable Energy Technologies, Suzhou, China and the Dr. Myung Ki Hong Chair in Materials Innovation (to R.B.K.).

\section{Author Contributions}

J.S., Y.S., R.K. and Z.L. conceived and designed the experiments. Z.T. and X.T. prepared the electrode materials and carried out the characterization, fabricated the $\mathrm{MgSO}_{4} / \mathrm{PAM}$ gel electrolyte, and fabricated the integrated self-powered device and investigated its photo-charging/discharging properties. Z.T. probed the reaction mechanisms using operando XRD and ex situ XPS. Z.T. fabricated the MASCs via printing, with L.Y.'s assistance. G.S., Y.S. and V.T. performed HRTEM and STEM mapping measurements. Z. T., Y.S., J.S., R.B.K. and Z.L. were mainly responsible for preparing the manuscript with input from all other authors. All authors discussed the results and commented on the manuscript. All authors have given approval to the final version of the manuscript.

\section{Competing Interests}

The authors declare no competing interests.

\section{Additional information}

Supplementary information is available for this paper at https://doi.org/10.1038/s41467019-12900-4.

Correspondence and requests for materials should be addressed to Y.S., J.S. or R.B.K.

Peer review information Nature communication thanks anonymous reviewers for their contribution to the peer review of this work. Peer review reports are available.

Reprints and permission information is available at http://www.nature.com/reprints

Publisher's note Springer Nature remains neutral with regard to jurisdictional claims in published maps and institutional affiliations.

(c) (i) Open Access This article is licensed under a Creative Commons Attribution 4.0 International License, which permits use, sharing, adaptation, distribution and reproduction in any medium or format, as long as you give appropriate credit to the original author(s) and the source, provide a link to the Creative Commons license, and indicate if changes were made. The images or other third party material in this article are included in the article's Creative Commons license, unless indicated otherwise in a credit line to the material. If material is not included in the article's Creative Commons license and your intended use is not permitted by statutory regulation or exceeds the permitted use, you will need to obtain permission directly from the copyright holder. To view a copy of this license, visit http://creativecommons.org/ licenses/by/4.0/.

(C) The Author(s) 2019 